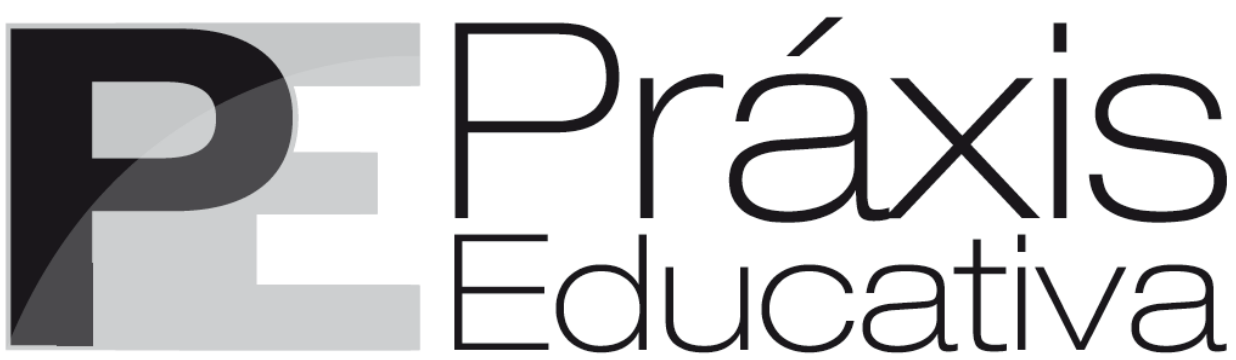

ISSN 1809-4309 (Versão online) DOI: 10.5212/PraxEduc.v.11i3.0019

\title{
LUCKESI, Cipriano Carlos. Sobre notas escolares: distorções e possibilidades. São Paulo: Cortez, 2014. 120 p.
}

Bruna Mayara Bonatto* Graciete Tozetto Góes ${ }^{* *}$

Carlos Cipriano Luckesi é reconhecido autor da área de avaliação educacional. Várias obras de sua autoria são referência sobre o tema da avaliação da aprendizagem. Luckesi é licenciado em Filosofia, bacharel em Teologia, Mestre em Ciências Sociais, pela Faculdade de Filosofia, e Ciências Humanas, pela Universidade Federal da Bahia e Doutor em Educação: Filosofia e História da Educação, pela Universidade Católica de São Paulo. Atualmente, é Professor pós-aposentado do Programa de Pós-Graduação da Faculdade de Educação (FACED) da Universidade Federal da Bahia (UFBA). Dentre as várias obras publicadas, destacam-se aquelas sobre o tema da avaliação: Prática docente e avaliação (1990), Avaliação da aprendizagem escolar (1995), Avaliação da aprendiragem na escola (2003), Avaliação da aprendizagem: componente do ato pedagógico (2011). Além do tema avaliação, o autor tem outras publicações com enfoque em Filosofia, em Filosofia da Educação e em Metodologia da Pesquisa ${ }^{1}$.

O maior desafio dos sistemas educativos, na atualidade, é o cumprimento do seu papel social de integrar o sujeito à sociedade da qual faz parte. Tal tarefa é cada vez mais difícil de tornar-se realidade, pois a cultura das práticas educacionais de ensino e avaliação ainda é predominantemente pautada em modelos que acabam por privilegiar um sistema de classificação e medidas, sem focar no processo de ensino e de aprendizagem.

Para compreensão do processo de ensino e de aprendizagem, faz-se necessária a análise crítica dos métodos de avaliação educacional e de sua utilização pelos educadores e gestores, os quais estão atrelados às políticas educacionais em uma dinâmica de codependência. Nessa direção, apresenta-se a obra Sobre notas escolares: distorções e possibilidades de Luckesi (Figura 1).

\footnotetext{
* Doutoranda em Educação (PPGE/UEPG). E-mail: <bruna.bonatto@hotmail.com>.

** Professora da Universidade Estadual de Ponta Grossa - Departamento de Pedagogia. Doutoranda em Educação (PPGE/UEPG). E-mail: <gtozetto@hotmail.com>.

${ }^{1}$ Dados obtidos no website de Cipriano Carlos Luckesi: <http://www.luckesi.com.br/apresentacao.htm>. Acesso em: 14 mar. 2016.
}

Práxis Educativa, Ponta Grossa, p. 855-860, v. 11, n. 3, set./dez. 2016 Disponível em: <http://www.revistas2.uepg.br/index.php/praxiseducativa> 
Figura 1 - Imagem da capa do livro Sobre notas escolares: distorções e possibilidades - 2014

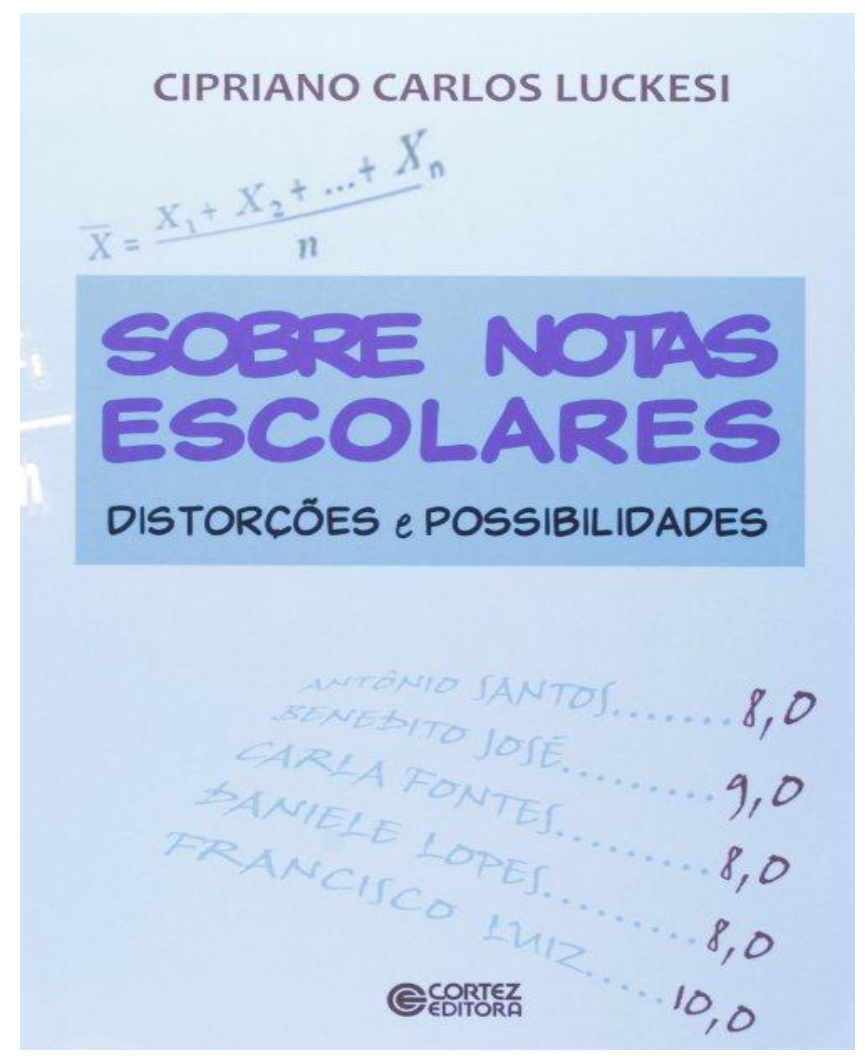

Fonte: Cortez Editora (2015).

A obra foi publicada em 2014 pela editora Cortez e está organizada em cinco capítulos assim denominados: capítulo I - Distorção epistemológica: contrabando entre qualidade e quantidade nas notas escolares; capítulo II - Distorção presente na prática das médias entre notas escolares; capítulo III Distorção nas notas escolares decorrente dos instrumentos de coleta de dados para avaliação; capítulo IV - O fetiche das notas escolares; capítulo V - Então, como registrar os resultados da aprendizagem dos nossos educandos?. Além dos capítulos elencados, o autor apresenta a introdução e as considerações finais.

O livro traz uma análise aprofundada sobre as notas escolares e como seu uso distorcido e equivocado prejudica a busca pela "qualidade plena" na educação. O autor explica, já na introdução, que a expressão "qualidade plena" é utilizada para "[...] afirmar que a aprendizagem do educando não pode ser pela 'média' ou por qualquer outra qualidade que não seja a aprendizagem satisfatória por parte do educando dos conteúdos que deveria aprender" (LUCKESI, 2014, p. 10, grifo do autor).

O primeiro capítulo, Distorção epistemológica: contrabando entre qualidade e quantidade nas notas escolares, apresenta o anexo: Por uma compreensão epistemológica da relação entre qualidade e quantidade, no qual o autor apresenta a relação entre quantidade e qualidade historicamente, iniciando pelos filósofos da antiguidade até o século XX. O texto é bastante elucidativo e complementa o exposto no primeiro capítulo.

Na primeira seção, o autor esclarece o sentido de epistemologia como área da Filosofia que discute as bases para considerar-se um conhecimento como válido. A crítica é elaborada considerando que "qualidade é qualidade" e "quantidade é quantidade", ou seja, são fenômenos 
distintos. A nota seria "[...] somente uma forma de registrar em documentos oficiais [...] o que o educando aprendeu com 'qualidade satisfatória' o que lhe fora ensinado [...]" (LUCKESI, 2014, p. 20, grifos do autor). No entanto, sua crítica aponta que, na prática, as notas escolares praticamente adquirem vida própria como se fosse "quantidade de qualidade".

Em sua análise epistemológica, o autor esclarece que “[...] qualidade não existe em si e por si” (LUCKESI, 2014, p. 21), ela é atribuída a algo, a um objeto de conhecimento que tem configuração própria. Por outro lado, quantidade "por si" não tem qualidade. A atribuição de qualidade dá-se em uma relação de conhecimento com o ser humano. A qualidade é agregada à realidade pelo ser humano, com base em critério socialmente estabelecido.

Partindo de exemplos, na segunda seção, o autor explica a quantidade e a qualidade na prática da avaliação da aprendizagem na escola. O texto leva o leitor a refletir sobre o sentido das expressões avaliação quantitativa e avaliação qualitativa e afirma: “[...] não existe 'avaliação quantitativa'; avaliação para efetivamente ser avaliação, implica que seja qualitativa, pois avaliação significa atribuir valor (qualidade) a um determinado objeto" (LUCKESI, 2014, p. 31, grifos do autor). Para esclarecer como surgem essas denominações e os efeitos dessa compreensão nas práticas escolares, o autor recorre a Lei $\mathrm{N}^{\circ}$ 5.692/1971 na qual se lê: “[...] preponderarão os aspectos qualitativos sobre os quantitativos [...]" (LUCKESI, 2014, p. 32), levando a interpretações indevidas. Um exemplo foi o entendimento de que aspectos qualitativos estavam relacionados a condutas e a elementos afetivos e que os aspectos quantitativos se referiam à quantidade de conteúdo. Nessa perspectiva, o texto é desafiador; ele convida o leitor a buscar superar essa distorção epistemológica da relação entre quantidade e qualidade.

No segundo capítulo, Distorção presente na prática das médias entre notas escolares, o autor propõe-se a analisar a prática das médias entre notas escolares e suas consequências na avaliação da aprendizagem. Para Luckesi, as médias obtidas entre notas escolares resultam em distorções sobre a aprendizagem dos alunos, bem como implica distorções na prática de ensino quando "[...] se investe menos que o necessário para que todos os educandos aprendam" (LUCKESI, 2014, p. $53)$.

O autor analisa as distorções tanto no uso das médias simples quanto no uso das médias ponderadas. O pesquisador argumenta que a média entre duas qualidades é "[...] um fenômeno material e epistemologicamente impossível" (LUCKESI, 2014, p. 54). Ele traz vários exemplos que demonstram essa impossibilidade. Ao final dessa seção, coerente com os pressupostos que utiliza, o autor afirma: "[...] não se pode compensar a aprendizagem de um determinado conteúdo pela aprendizagem de outro". "[...] os educandos são promovidos de série em série por notas médias e não por aprendizagem plena nos diversos tópicos de conteúdos" (LUCKESI, 2014, p. 56-57, grifos do autor).

No terceiro capítulo, intitulado Distorção nas notas escolares decorrente dos instrumentos de coleta de dados para a avaliação, Luckesi acrescenta às distorções epistemológicas e às das médias apresentadas nos capítulos anteriores - a distorção que emerge dos instrumentos utilizados para coleta de dados para a avaliação da aprendizagem dos educandos. $O$ autor sustenta que os instrumentos de coleta de dados para a avaliação consistem em um recurso metodológico quando utilizados no contexto educacional, pois são esses instrumentos que solicitam ao educando que mostrem seu nível de aprendizado acerca do conteúdo ensinado. Para ele, a falta de cuidado no tratamento metodológico na elaboração dos instrumentos de coletas de dados para a avaliação pode gerar uma distorção referente ao desempenho dos educandos. "E, então, podemos concluir que, se os dados sobre os quais se assentam as notas escolares são distorcidas em função dos instrumentos utilizados para sua coleta, elas também são distorcidas, isto é, não apresentam uma realidade" (LUCKESI, 2014, p. 73).

Práxis Educativa, Ponta Grossa, p. 855-860, v. 11, n. 3, set./dez. 2016 Disponível em: <http://www.revistas2.uepg.br/index.php/praxiseducativa> 
Seguindo com a crítica à distorção oriunda dos instrumentos de coleta de dados para a avaliação, Luckesi aponta quatro das fragilidades mais comuns nesse momento da avaliação da aprendizagem dos educandos. A primeira é a falta de sistematicidade, ou seja, o instrumento de coleta de dados não contempla todo o conteúdo ensinado, mas apenas uma parcela dele, o que dá a esse instrumento a característica de aleatoriedade. Em seguida, o autor aponta que a falta de linguagem compreensível é outro fator que contribui para a distorção nos dados obtidos pelos instrumentos de coletas, pois, usualmente, os instrumentos são redigidos com uma linguagem mais complexa do que aquela utilizada durante o ensino do conteúdo.

A terceira fragilidade apontada pelo autor é a incompatibilidade entre os níveis de dificuldade, entre os níveis de complexidade e a incompatibilidade metodológica referente aos conteúdos ensinados e os que foram solicitados no instrumento de coleta de dados para a avaliação. Por fim, a falta de precisão - concebida como a capacidade de investigador e investigado interpretarem de maneira equivalente o conteúdo de uma questão - é indicada pelo autor como a quarta fragilidade encontrada nos instrumentos de coleta de dados para a avaliação da aprendizagem.

Em síntese, o terceiro capítulo explica como os dados obtidos por meio de instrumentos de coletas de dados com tantas fragilidades metodológicas não fornecem uma descritiva fidedigna da realidade. Dessa forma, "[...] ocorrendo distorção na coleta de dados, as notas atribuídas ao educando com base em dados coletados nessas condições não podem representar efetivamente sua aprendizagem" (LUCKESI, 2014, p. 80). Para além do exposto, o autor orienta que essas práticas são perpetuadas pelo educador no cotidiano escolar pela reprodução não deliberada e que se faz necessária uma mudança de consciência e de conduta por novas práticas que adotem cuidados metodológicos na elaboração de instrumentos de coleta de dados.

No quarto capítulo, O fetiche das notas escolares, Luckesi trata das notas escolares de acordo com os preceitos do materialismo dialético, utilizando o conceito de fetiche. De acordo com o autor, retomando os exemplos dos capítulos anteriores nos quais ele demonstrou como as notas escolares e as operações aritméticas fazem o desempenho do estudante saltar indevidamente da "qualidade" para a "quantidade", as notas escolares "[...] atuam de forma autônoma, independente da qualidade da aprendizagem dos educandos" e estão imbuídas em distorções por “[...] terem recebido uma realidade que não tem" (LUCKESI, 2014, p. 83-84).

Luckesi apontou, nos capítulos anteriores, as distorções epistemológicas, as distorções das médias e as distorções dos instrumentos utilizados para coleta de dados para a avaliação, demonstrando que as notas escolares "[...] com seus malabarismos operacionais, não revelam a qualidade da aprendizagem dos educandos devido operar descoladas dela”. Segundo o autor, isso tudo ocorre "[...] pelo fetiche das notas escolares, que registram supostas expressões da qualidade da aprendizagem dos educandos, mas que, efetivamente, operam por si mesmas, descoladas das qualidades que representariam" (LUCKESI, 2014, p. 93).

Uma das consequências da tradição das notas escolares, apontadas pelo autor, é a formação de estudantes que atingem a média para aprovação, mas que possuem várias lacunas na aprendizagem. Outra implicação é que a aprovação pela média desobriga as instituições de ensino e os educadores a ofertar um sistema de ensino-aprendizagem de melhor qualidade, para além da operacionalização da média.

Ao concluir o capítulo, Luckesi denota a preocupação política e social ao abordar as notas escolares como fetiche no sistema educacional vigente no país. Para ele, as notas escolares reproduzem a exclusão social, pois atuam contra um modelo educacional democrático que teria como objetivo "[...] um ensino de qualidade, um ensino em que todos aprendem o necessário

Práxis Educativa, Ponta Grossa, p. 855-860, v. 11, n. 3, set./dez. 2016 Disponível em: <http://www.revistas2.uepg.br/index.php/praxiseducativa> 
dentro de uma determinada cultura num determinado momento histórico" (LUCKESI, 2014, p. 97). A solução apontada é o investimento "na qualidade de ensino-aprendizagem" para que “todos os estudantes” (LUCKESI, 2014, p. 98) possam aprender o necessário.

No quinto capítulo, Então, como registrar os resultados da aprendizagem dos nossos educandos?, o autor aponta as possibilidades para a superação das distorções das notas escolares. Na primeira seção, denominada A prática presente em nossas escolas, Luckesi retoma as distorções apontadas nos três primeiros capítulos, destacando que as "[...] notas escolares não formam, mas aprendizagem sim" (LUCKESI, 2014, p. 101). Para o autor, a nota escolar da maneira como é compreendida hoje precisa ser substituída pelo registro da qualidade da aprendizagem do estudante em uma perspectiva que se trabalhe "[...] para que cada educando aprenda o necessário, ou seja, ensinar bem, que é um ato mais complexo do que 'dar aulas"' (LUCKESI, 2014, p. 102, grifo do autor).

$\mathrm{Na}$ segunda seção do capítulo, intitulada Então, como registrar o testemunho da qualidade da aprendizagem ?, o autor sugere uma nova forma para o registro da qualidade da aprendizagem dos educandos nas escolas. Luckesi destaca a importância do registro da qualidade da aprendizagem do educando em um período letivo retomando as descrições do terceiro capítulo acerca dos cuidados metodológicos com o instrumento de coleta de dados para a avaliação da aprendizagem. Em seguida, o autor orienta que é importante que o instrumento de coleta de dados permita ao estudante manifestar que compreendeu suficientemente bem todos os conteúdos, mas caso não tenha demonstrado uma aprendizagem satisfatória "[...] deverá ser reorientado para que aprenda e até que aprenda" (LUCKESI, 2014, p. 107).

O autor orienta, ainda, que, com esse modelo, é possível atingir o "[...] nível de satisfatoriedade plena da aprendizagem" e "[...] será o investimento na qualidade da aprendizagem que produzirá a satisfatoriedade" (LUCKESI, 2014, p. 107). Após ser conquistada a "qualidade plena" da aprendizagem, ela poderá ser registrada de acordo com uma simbologia (números, letras, entre outros) definida em comum acordo pela comunidade da instituição de ensino e será utilizada como "[...] expressão da qualidade plena da aprendizagem e não como recurso para as médias” (LUCKESI, 2014, p. 108).

Por fim, Luckesi sustenta que, ao direcionar as práticas pedagógicas para que todos atinjam o mínimo necessário, se amplia a possibilidade da democratização do ensino. Além disso, exige do sistema de ensino, tanto quanto dos educadores, um maior comprometimento e investimento na "aprendizagem satisfatória dos estudantes" (LUCKESI, 2014, p. 109).

Nas considerações finais, Luckesi afirma que é possível atingir a qualidade plena de aprendizagem, mesmo diante das dificuldades postas no cotidiano escolar, se houver investimentos significativos no sentido do ato de ensinar. Para o autor, o processo de avaliação está diretamente relacionado ao processo de aprendizagem e o educador precisa debruçar-se sobre a realidade, mais focado na solução do que no problema, para encontrar melhores resultados.

A importância da leitura dessa obra está em retomar o sentido da avaliação da aprendizagem compreendendo-a, para além das notas escolares, como parte integrante do processo de ensino-aprendizagem. Luckesi possibilita uma reflexão para todos aqueles envolvidos com processos avaliativos: professores dos diferentes níveis de ensino, coordenadores pedagógicos e gestores. Para além do exposto, as orientações do autor corroboram com um projeto de sociedade democrática na perspectiva de uma educação de qualidade para todos.

Práxis Educativa, Ponta Grossa, p. 855-860, v. 11, n. 3, set./dez. 2016 Disponível em: <http://www.revistas2.uepg.br/index.php/praxiseducativa> 


\section{Referência}

CORTEZ Editora. Sobre notas escolares - distorções e possibilidades - Cipriano Luckesi. 2015. Disponível em: <http://www.cortezeditora.com.br/sobre-notas-escolares-distorcoes-epossibilidades-1457.aspx/p>. Acesso em: 7 jun. 2016. 